\title{
Ethanol-induced colitis prevents oral tolerance induction in mice
}

M.C. Andrade,

N.M. Vaz and

A.M.C. Faria
Departamento de Bioquímica e Imunologia, Instituto de Ciências Biológicas, Universidade Federal de Minas Gerais, Belo Horizonte, MG, Brasil

\footnotetext{
Correspondence

A.M.C. Faria

Departamento de Bioquímica e

Imunologia, ICB, UFMG

Av. Antônio Carlos, 6627

31270-901 Belo Horizonte, MG

Brasil

Fax: +55-31-3499-2640

E-mail: afaria@icb.ufmg.br
}

Received April 7, 2003

Accepted June 3, 2003

\begin{abstract}
The gut mucosa is a major site of contact with antigens from food and microbiota. Usually, these daily contacts with natural antigens do not result in inflammatory reactions; instead they result in a state of systemic hyporesponsiveness named oral tolerance. Inflammatory bowel diseases (IBD) are associated with the breakdown of the immunoregulatory mechanisms that maintain oral tolerance. Several animal models of IBD/colitis are available. In mice, these include targeted disruptions of the genes encoding cytokines, T cell subsets or signaling proteins. Colitis can also be induced by intrarectal administration of chemical substances such as 2,4,6-trinitrobenzene sulfonic acid in $50 \%$ ethanol. We report here a novel model of colitis induced by intrarectal administration of 50\% ethanol alone. Ethanol-treated mice develop an inflammatory reaction in the colon characterized by an intense inflammatory infiltrate in the mucosa and submucosa of the large intestine. They also present up-regulation of both interferon gamma (IFN- $\gamma$ ) and interleukin-4 (IL-4) production by cecal lymph node and splenic cells. These results suggest a mixed type of inflammation as the substrate of the colitis. Interestingly, cells from mesenteric lymph nodes of ethanol-treated mice present an increase in IFN- $\gamma$ production and a decrease in IL-4 production indicating that the cytokine balance is altered throughout the gut mucosa. Moreover, induction of oral tolerance to ovalbumin is abolished in these animals, strongly suggesting that ethanol-induced colitis interferes with immunoregulatory mechanisms in the intestinal mucosa. This novel model of colitis resembles human IBD. It is easy to reproduce and may help us to understand the mechanisms involved in IBD pathogenesis.
\end{abstract}

Key words

- Ethanol

- Colitis

- Oral tolerance

- Cytokines
The gut mucosa is constantly and physiologically exposed to a large variety of antigenic material represented by dietary proteins and bacterial antigens. These antigens contact a large and complex gut-associated lymphoid tissue that is mainly located in the small intestine (1). Interestingly, the major immunological consequence of the chronic stimulation of lymphocytes in the gut mu- cosa is a state of systemic hyporesponsiveness, named oral tolerance, to subsequent parenteral challenges with the same antigen $(2,3)$. Many mechanisms have been shown to be involved in the induction of oral tolerance such as active suppression, anergy and clonal deletion (3). Active suppression is based on the generation of regulatory cells following antigenic contact in the gut-asso- 
ciated lymphoid tissues that act mostly via secretion of down-regulatory cytokines such as transforming growth factor- $\beta$ (TGF- $\beta$ ) $(4,5)$ and interleukin-10 (IL-10) (6). The mechanisms by which these regulatory cells are induced are not known, but it is clear that features of the gut microenvironment are extremely important. Under normal conditions, the intestinal environment presents high levels of cytokines such as IL-10, TGF$B$ and IL-4 that are believed to be important in the establishment of regulatory events and in the inhibition of inflammatory responses (3). Other local anti-inflammatory mediators are likely to play a role. Moreover, mucosal lymphocytes usually express markers of chronically activated cells (CD45RB ${ }^{\text {low }}, \alpha 4 \beta 7$ and $\alpha E$ B7 integrins, $C D 62 L^{\text {low }}, C D 44^{\text {high }}$ ), some of which have also been identified as suppressor cell markers $(5,6)$.

A breakdown of these multiple regulatory mechanisms is usually associated with inflammatory intestinal pathologies. Inflammatory bowel diseases (IBD) such as Crohn's disease and ulcerative colitis are chronic relapsing inflammatory diseases of the gastrointestinal tract. Several manipulations of key elements of the immune system are reported to induce IBD in mice. Mice genetically deficient in either IL-2 (7) or IL-10 (8) develop an IBD that affects multiple sites in the intestinal tract, suggesting that disruption in these genes interferes with the generation of regulatory mechanisms in the gut. Similarly, IBD develop in mice with alterations in T cell subsets, such as T cell receptor- $\alpha$-deficient mice (9), and in severe combined immunodeficient mice reconstituted with CD4+ $\mathrm{T}$ cell subsets (5). In addition, colitis can be induced by the rectal administration of peptidoglycan-polysaccharide polymers in rats, dextran sulfate sodium, oxazolone or the contact sensitizing allergen 2,4,6trinitrobenzene sulfonic acid (TNBS) in 50\% ethanol in mice (10). These agents are believed to act as stressors of the mucosa triggering an inflammatory process that is en- hanced by local bacterial stimulation. Intestinal lesions in the models of IBD resemble those seen in the human disease and include the presence of extensive leukocytic infiltrates, epithelial cell hyperplasia, depletion of mucin-secreting cells and, in some cases, ulceration.

The best described model of agent-induced colitis is the TNBS-induced colitis in which TNBS is believed to act by haptenizing colonic cells. TNBS colitis appears to be a classic delayed type hypersensitivity response mediated by $\mathrm{T}$ cells responding to "haptenmodified self-antigen" formed by the covalent attachment of the hapten, trinitrophenyl, to self-proteins (11). Ethanol is used as a vehicle for TNBS although it is known to cause a local irritation.

We describe here a novel experimental model of colitis that is induced by administration of $50 \%$ ethanol alone. Colitis was induced in 8-week-old BALB/c mice by two intrarectal administrations of ethanol 5 days apart. Intrarectal procedures were performed using a straight gavage needle with either $200 \mu \mathrm{l} \mathrm{50 \%}$ ethanol in saline (w/v), pH 7.0, or only $200 \mu \mathrm{l}$ saline as a control. Seventytwo hours after the last administration was determined to be the optimal time for the inflammatory reaction in the colon as demonstrated by histological analyses. At that time, animals were sacrificed by cervical dislocation. The stomach, small and large intestines, and liver were excised, washed with cooled PBS and fixed in 10\% PBSbuffered formalin for $24 \mathrm{~h}$. After paraffin embedding, 4- $\mu \mathrm{m}$ thick transverse sections of the tissues were obtained, stained with hematoxylin and eosin and examined under a light microscope.

Mice developed an inflammatory reaction in the colonic mucosa and submucosa characterized by an infiltrate of mono- and some polymorphonuclear cells that formed lymphoid aggregates, disruption of mucosal integrity and some erosive spots on the epithelial surface. These alterations resulted in 
loss of mucosal integrity (Figure 1B). There was no sign of inflammation in the other isolated tissues (data not shown). Cytokine production by cells from several lymphoid organs was measured by culturing isolated cells $\left(1 \times 10^{7}\right.$ cells $\left./ \mathrm{ml}\right)$ in the presence of 4 $\mu \mathrm{g} / \mathrm{ml}$ concanavalin A for $72 \mathrm{~h}$ (Figure 1C,D). Culture supernatants were tested by ELISA for interferon- $\gamma($ IFN- $\gamma$ ) (Figure 1C) and IL-4 (Figure 1D). Cells from draining lymph nodes (cecal) and from a systemic lymphoid organ (spleen) from ethanol-treated mice produced significantly higher levels of IFN- $\gamma$ and IL-4 compared to cells from control mice, suggesting that a mixed inflammatory reaction is triggered by ethanol. Although some investigators have described TNBS-induced colitis as a typical delayed type hypersensitivity reaction with a predominance of IFN- $\gamma$ production (11), others have reported that, in $\mathrm{BALB} / \mathrm{c}$ mice, the initial production of IFN- $\gamma$ is followed by a predominant local IL-4 secretion (10). Whether a Th1- or a Th2-type of response prevails has a considerable impact on the nature of the inflammation since IFN- $\gamma$ production is associated with trans-
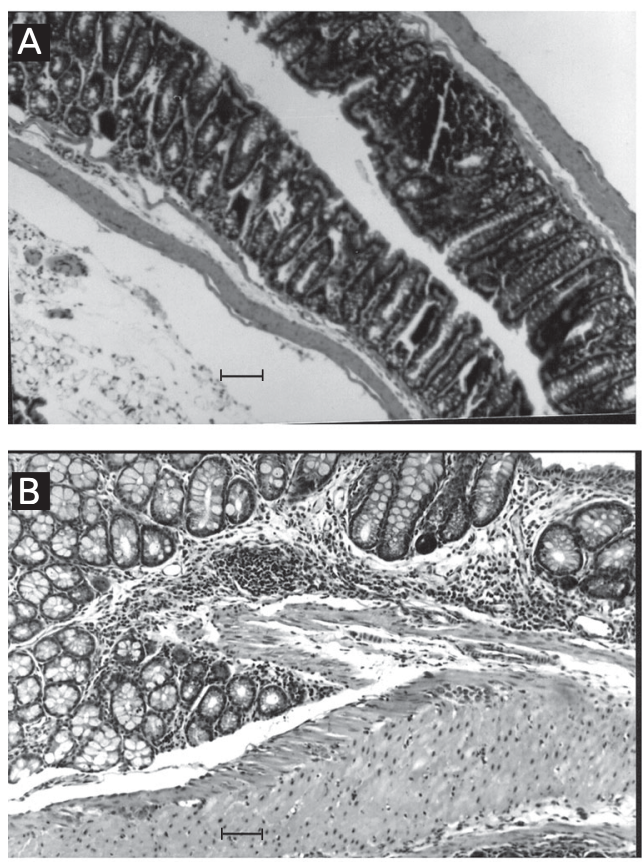

mural cellular infiltration that, in some cases, results in granuloma formation. On the other hand, IL-4 and IL-5 production is associated with more superficial cellular infiltrates, a greater disruption of the epithelial layer and polymorphonuclear infiltrates. This type of inflammation is observed in some experimental models such as $T$ cell receptor- $\alpha$ knockout mice, oxazolone-induced colitis and WASP deficiency (10). Human ulcerative colitis seems to present both components, being characterized as a mixed inflammatory reaction (12). Our model seems to be more related to this type of inflammatory disease as shown by cytokine production (Figure 1C,D) and by the local cellular infiltrate (Figure 1B).

Interestingly, mesenteric lymph node cells from ethanol-treated mice produced higher levels of IFN- $\gamma$ and lower levels of IL-4 than cells from control mice. Mesenteric lymph nodes drain the small intestine, the region of the gut where dietary protein absorption takes place and where most of the gut-associated lymphoid tissue is located (1). The lymphoid gut environment is a complex interplay of
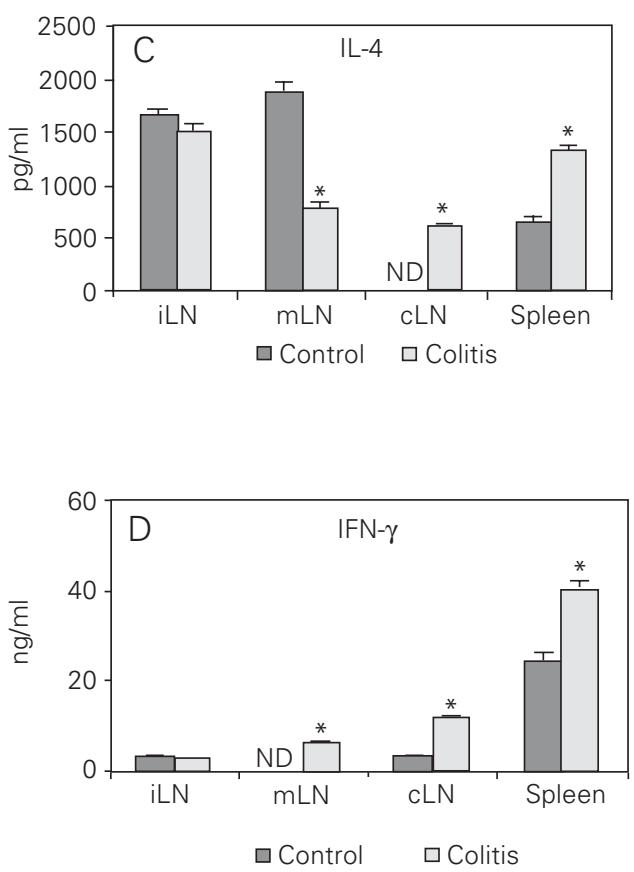

Figure 1. Effect of intrarectal ethanol administration on colon morphology $(A, B)$ and cytokine production by lymphoid organs (C, D). Mice received one intrarectal administration of either $0.2 \mathrm{ml}$ saline ( $\mathrm{A}$, and dark gray columns in $C$ and D) or $50 \%$ ethanol $(B$, and light gray columns in $C$ and $D$ ) and were challenged with either saline or ethanol intrarectally 5 days later. Three days later, histological analysis of the large intestine was performed (A, B). Tissue was stained with hematoxylin and eosin. Inguinal (iLN), mesenteric (mLN) and cecal (cLN) lymph nodes as well as spleen cells were isolated, stimulated in vitro with concanavalin $A$ and supernatants were collected $72 \mathrm{~h}$ later to measure cytokine production by quantitative ELISA (C, D). $P<0.05$ compared to control mice (unpaired $t$-test). $\mathrm{ND}=$ not determined. Magnification bars: $A=50 \mu \mathrm{m} ; B=30$ $\mu \mathrm{m}$. 
Figure 2. Effect of the induction of colitis on oral tolerance to ovalbumin (Ova). Mice received one intrarectal administration of $0.2 \mathrm{ml}$ saline (control) or $50 \%$ ethanol (colitis) and were challenged with saline and ethanol intrarectally, respectively, 5 days later. Three days later, mice were fed either Ova (light gray columns) or saline (dark gray columns). After 7 days, all animals received an intraperitoneal injection of $10 \mu \mathrm{g}$ Ova in $3 \mathrm{mg} \mathrm{Al}(\mathrm{OH})_{3}$ and were boosted with $10 \mu \mathrm{g}$ Ova 14 days later. Sera from all mice were collected 7 days after the booster and serum-specific antibodies were measured by ELISA. Data are presented as the mean of the running sum of absorbances at dilutions of $1: 800$ to $1: 6400$ in the ELISA test and significant differences between groups were calculated by the two-tailed Student t-test. $P<0.05$ compared to control saline-fed mice (unpaired $t$-test). mediators and cells that are constantly activated towards a regulatory immunological pattern probably responsible for oral tolerance induction. Several mechanisms can account for the predominantly regulatory activity of the gut-associated lymphoid cells and locally produced cytokines are among them (3). Isolated cells from Peyer's patches and mesenteric lymph nodes produce high levels of IL-10 and IL-4 when stimulated in culture by polyclonal activators, whereas splenic cells produce mostly IFN- $\gamma$ (13). Moreover, TGF- $\beta$ and IL-10 are abundant cytokines in the gut milieu and are clearly involved in suppression of inflammatory reactions in the gut (5) and in oral tolerance induction $(3,14)$. The switch in IL-4/IFN- $\gamma$ production by mesenteric lymph node cells observed upon colitis induction suggests that ethanol treatment interferes with the cytokine balance throughout the gut mucosa. It also indicates that regulatory mechanisms that maintain oral tolerance may be disturbed.

Therefore, the next step was to study oral tolerance development in these animals. Ethanol-treated and control mice were tested for the induction of oral tolerance using a single intragastric administration of $20 \mathrm{mg}$ ovalbumin (Ova) as a tolerogenic procedure. Mice were fed $72 \mathrm{~h}$ after the last ethanol treatment, immunized with $10 \mu \mathrm{g}$ Ova in $3 \mathrm{mg} \mathrm{Al}(\mathrm{OH})_{3}$ 7 days thereafter, and boosted with $10 \mu \mathrm{g}$ soluble Ova 14 days later. Sera were collected 7 days after the booster for specific antibody measurements by standard ELISA.

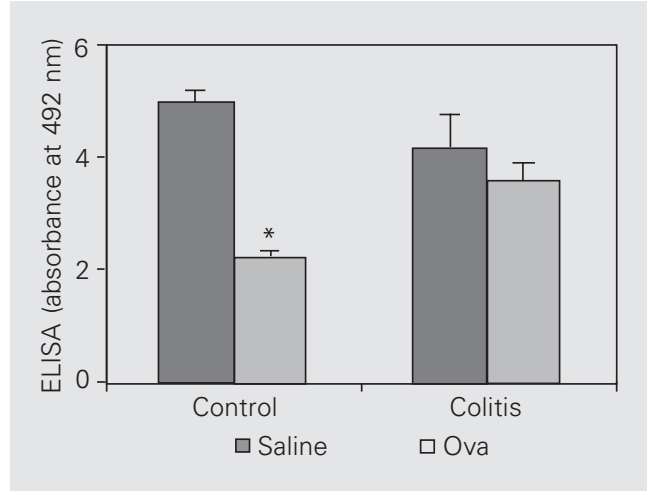

For the ELISA test, plates were sensitized with $2 \mu \mathrm{g}$ Ova, blocked with a solution containing $0.25 \%$ casein and incubated with serial dilutions of serum samples. To visualize bound anti-Ova antibodies, horseradish peroxidase-conjugated goat anti-mouse Ig antibodies were used and the reaction was developed in the presence of $\mathrm{H}_{2} \mathrm{O}_{2}$ and orthophenylenediamine. The reaction was stopped with $\mathrm{H}_{2} \mathrm{SO}_{4}$ and absorbance was read at 492 nm.

As shown in Figure 2, oral tolerance induction for specific antibody production was abolished in ethanol-treated mice. This result suggests that immunoregulatory mechanisms in the gut are affected by ethanol-induced colitis. It is likely that ethanol acts not only as an irritant breaking the mucosal barrier of epithelial cells, but also as a stressor that interferes with antigen presentation and cytokine production. Both types of actions may interfere with oral tolerance to microbiota antigens and trigger an inflammatory reaction to otherwise innocuous bacteria.

The present results agree with recent studies showing that ethanol is a potent inhibitor of glutathione synthesis and that glutathione levels in antigen-presenting cells are an important factor in the prevalence of the Th1 versus Th2 profile of immune responses (15). Inhibition of glutathione affects the ability of spleen antigen-presenting cells to produce IL-12, as already described in other models, compromising IFN- $\gamma$ production by $\mathrm{T}$ cells and allowing the development of IL-4producing $\mathrm{T}$ cells. Although reports on active suppression in oral tolerance induction agree that the predominance of a Th2 profile in the gut microenvironment is crucial to the development of the phenomenon (16), overproduction of IL-4 may trigger Th2-type inflammatory events (17). This would help to explain the up-regulation of IL-4 by cecal and spleen cells in our model. On the other hand, ethanol may have other irritant and inflammatory effects that stimulate IFN- $\gamma$ 
production by local and systemic lymphocytes. Interference with oral tolerance to components of the microbiota is certainly a major inflammatory mechanism that may trigger IFN- $\gamma$ production. It has been already demonstrated that oral tolerance to normal microbiota is abolished in Crohn's disease (18) and in mice with experimental colitis (19). In addition, for several models of colitis, inflammatory disease either does not develop or is reduced in germ-free animals and in antibiotic-treated animals, suggesting that immunological reaction to enteric bacteria has a major impact on disease expression (20). In agreement with these previous results, our data show that the immunoregulatory mechanisms triggered by oral tolerance induction are impaired by ethanol treatment and suggest that an inflammatory reaction to the intestinal microbiota may be involved in colitis development.
We report a novel model of colitis that is induced by administration of ethanol alone and seems to bear some resemblance to human IBD such as ulcerative colitis. Ethanolinduced colitis interferes with cytokine production throughout the intestinal mucosa as well as systemically and also abolishes the induction of oral tolerance. This novel model is easy to reproduce and may be useful to study the mechanisms involved in immunoregulation triggered by oral administration of antigen and the pathogenesis of IBD. It also sheds some light on the immunological effects of ethanol.

\section{Acknowledgments}

We thank Ms. Frankcinéia Aparecida de Assis and Ms. Ilda Martins Marçal de Souza for excellent technical assistance.

\section{References}

1. Mowat AM \& Viney JL (1997). The anatomical basis of intestinal immunity. Immunological Reviews, 156: 145-166.

2. Vaz NM, de Souza CM, Hornbrook MM, Hanson DG \& Lynch NR (1977). Sensitivity to intravenous injections of histamine and serotonin in inbred mouse strains. International Archives of Allergy and Applied Immunology, 53: 545-554

3. Faria AMC \& Weiner HL (1999). Oral tolerance: mechanisms and therapeutic applications. Advances in Immunology, 73: 153-264.

4. Miller A, Lider O, Roberts AB, Sporn MB \& Weiner HL (1992). Suppressor $T$ cells generated by oral tolerization to myelin basic protein suppress both in vivo and in vitro immune response by the release of transforming growth factor beta after antigen-specific triggering. Proceedings of the National Academy of Sciences, USA, 89: 421-425.

5. Powrie F, Carlino J, Leach MW, Mauze S \& Coffman RL (1996). A critical role for transforming growth factor-beta but not interleukin 4 in the suppression of $T$ helper type 1-mediated colitis by CD45RB(low) CD4+ T cells. Journal of Experimental Medicine, 183: 2669-2674.

6. Asseman C, Mauze S, Leach MW, Coffman RL \& Powrie F (1999). An essential role for interleukin 10 in the function of regulatory $T$ cells that inhibit intestinal inflammation. Journal of Experimental Medicine, 190: 995-1004.

7. Sadlack B, Merz H, Schorle H, Schimpl A, Feller AC \& Horak I (1993). Ulcerative colitis-like disease in mice with a disrupted interleukin-2 gene [see comments]. Cell, 75: 253-261.

8. Kuhn R, Lohler J, Rennick D, Rajewsky K \& Muller W (1993). Interleukin-10-deficient mice develop chronic enterocolitis. Cell, 75: 263-274
9. Mombaerts P, Mizoguchi E, Grusby MJ, Glimcher LH, Bhan AK \& Tonegawa S (1993). Spontaneous development of inflammatory bowel disease in T cell receptor mutant mice. Cell, 75: 274-282.

10. Strober W, Fuss IJ \& Blumberg RS (2002). The immunology of mucosal models of inflammation. Annual Review of Immunology, 20: 495-549.

11. von Bonin A, Ortmann B, Martin S \& Weltzien HU (1992). Peptideconjugated hapten groups are the major antigenic determinants for trinitrophenyl-specific cytotoxic T cells. International Immunology, 4: 869-874.

12. Fuss IJ, Neurath M, Boirivant M, Klein JS, de la Motte C, Strong SA, Fiocchi C \& Strober W (1996). Disparate CD4+ lamina propria (LP) lymphokine secretion profiles in inflammatory bowel disease. Crohn's disease LP cells manifest increased secretion of IFNgamma, whereas ulcerative colitis LP cells manifest increased secretion of IL-5. Journal of Immunology, 157: 1261-1270.

13. Iwasaki A \& Kelsall BL (1999). Freshly isolated Peyer's patch, but not spleen, dendritic cells produce interleukin 10 and induce the differentiation of $\mathrm{T}$ helper type 2 cells. Journal of Experimental Medicine, 190: 229-239.

14. Rizzo LV, Morawetz RA, Miller-Rivero NE, Choi R, Wiggert B, Chan C-C, Morse III HC, Nussenblatt RB \& Caspi RR (1999). IL-4 and IL-10 are both required for the induction of oral tolerance. Journal of Immunology, 162: 2613-2622.

15. Peterson JD, Herzenberg LA, Vasquez K \& Waltenbaugh C (1998). Glutathione levels in antigen-presenting cells modulate Th1 versus Th2 response patterns. Proceedings of the National Academy of Sciences, USA, 95: 3071-3076.

16. Khoury SJ, Hancock WW \& Weiner HL (1992). Oral tolerance to 
myelin basic protein and natural recovery from experimental autoimmune encephalomyelitis are associated with downregulation of inflammatory cytokines and differential upregulation of transforming growth factor b, interleukin 4, and prostaglandin E expression in the brain. Journal of Experimental Medicine, 176: 13551364.

17. Russo M, Nahori MA, Lefort J et al. (2001). Suppression of asthmalike responses in different mouse strains by oral tolerance. American Journal of Respiratory Cell and Molecular Biology, 24: 518-526.

18. Landers CJ, Cohavy O, Misra R, Yang H, Lin YC, Braun J \& Targan SR (2002). Selected loss of tolerance evidenced by Crohn's dis- ease-associated immune responses to auto- and microbial antigens. Gastroenterology, 123: 689-699.

19. Duchmann R, Schmitt E, Knolle P, Meyer zum Büschenfelde KH \& Neurath M (1996). Tolerance towards resident flora in mice is abrogated in experimental colitis and restored by treatment with interleukin-10 or antibodies to interleukin-12. European Journal of Immunology, 26: 934-938.

20. Elson CO, Sartor RB, Tennyson GS \& Riddell RH (1995). Experimental models of inflammatory bowel disease. Gastroenterology, 109: 1344-1367. 